\title{
Effects of Biopolymer Surfactants on the Morphology and Optical Properties of Zinc Sulphide (ZnS) Nanocrystalline Thin Film
}

\author{
Dorathy Awing Avit, ${ }^{1}$ Suk-Fun Chin,${ }^{* *}$ Noor Azie Azura Mohd Arif ${ }^{2}$ \\ and Sahbudin Shaari ${ }^{3}$ \\ ${ }^{1}$ Faculty of Resource Science and Technology, Universiti Malaysia Sarawak, \\ 94300 Kota Samarahan, Sarawak, Malaysia \\ ${ }^{2}$ Centre for Pre-University Studies, Universiti Malaysia Sarawak, \\ 94300 Kota Samarahan, Sarawak, Malaysia \\ ${ }^{3}$ Institute of Microengineering and Nanoelectronics, Universiti Kebangsaan Malaysia, \\ 43600 Bangi, Selangor, Malaysia \\ ${ }^{*}$ Corresponding author: sfchin@unimas.my
}

Published online: 25 November 2019

To cite this article: Avit, D. A. et al. (2019). Effects of biopolymer surfactants on the morphology and optical properties of zinc sulphide $(\mathrm{ZnS})$ nanocrystalline thin film. J. Phys. Sci., 30(3), 191-206, https://doi.org/10.21315/jps2019.30.3.12

To link to this article: https://doi.org/10.21315/jps2019.30.3.12

\begin{abstract}
Particle sizes of nanoparticles have significant effects on thin film properties such as the morphological and optical properties. However, controlling the size and morphology is a challenging task. One of the approaches towards overcoming these challenges is by using surfactants. This study reported the effects of several types of biopolymer surfactants on the size of zinc sulphide (ZnS) nanoparticles and the morphology of ZnS nanocrystalline thin films. The ZnS nanocrystalline thin films were fabricated by the spin-coating of ZnS nanoparticles on APTES [(3-aminopropyl) triethoxysilane] functionalised silica glass. Alginic acid, chitosan and starch were used as the surfactants to control the morphological and optical properties of the thin films. The XRD analysis confirmed the cubic structure and crystalline nature of the ZnS thin films. The field emission scanning electron microscope (FESEM) analysis revealed that the mean particle size of the ZnS nanocrystalline thin film to be with in the range of 20-30 nm. The optical measurements revealed that all ZnS thin films exhibited a high transmittance of $92 \%-99 \%$ in the visible range. Photoluminescence (PL) spectra for all thin films were determined and exhibited their respective peaks at $470 \mathrm{~nm}$ and $620 \mathrm{~nm}$.
\end{abstract}

Keywords: Zinc sulphide, spin coating, biopolymer surfactant, nanocrystalline, thin film 


\section{INTRODUCTION}

Zinc sulphide $(\mathrm{ZnS})$ is a nontoxic II-VI compound semiconductor that has the novel properties of a wide direct band gap of 3.65-3.7 eV. ${ }^{1}$ In view of its wide band gap value, $\mathrm{ZnS}$ thin films can be applied for the fabrication of optoelectronic devices, such as optical sensors, solar cells, anti-reflecting coatings and electroluminescent displays. ${ }^{2,3}$ The most significant feature of $\mathrm{ZnS}$ nanocrystal is their chemical and physical properties that differ greatly from those of their bulk counterparts. Due to ZnS' unique characteristics, many researchers have been interested to synthesise and study the properties of the its nanostructures. There are many methods available to synthesise $\mathrm{ZnS}$ nanoparticles, such as sol-gel, chemical precipitation method, inert gas condensation technique, ultrasonic radiation and hydrothermal process. ${ }^{4-8}$ Meanwhile, there are several different thin film deposition techniques such as spin coating, dip coating, chemical bath deposition, chemical spray pyrolysis and microwave irradiation. , $^{1,5-11}$

One of the greatest challenges in synthesising nanoparticles is attaining a precise control for the nanoparticle size and the morphology of the resultant thin films, as most nanostructures will undergo aggregation and agglomeration. ${ }^{12,13}$ In recent years, tremendous efforts have been focused on using the surfactants like cetyltrimethylammonium bromide (CTAB), Triton x-100, cetyltrimethylammonium chloride (CTAC), polyvinylpyrrolidone (PVP), polyvinyl alcohol (PVA) and polyethylene glycol (PEG) for tailoring the morphology of the thin films. Such incorporation will also subsequently to finetune their optical properties for various specific applications. ${ }^{10,12-17}$ To the best of authors' knowledge, the use of biopolymers as the surfactant for the fabrication of $\mathrm{ZnS}$ thin films has not been explored extensively. Biopolymers are relatively low-cost, non-toxic, renewable and abundantly available, rendering them to be promising as surfactants for the fabrication of $\mathrm{ZnS}$ thin film. ${ }^{18,19} \mathrm{In}$ this study, $\mathrm{ZnS}$ nanocrystalline thin films were fabricated by using the combined techniques of solgel and spin coating method. The effects of various biopolymer-based surfactant like starch, alginic acid and chitosan on the morphology and optical properties of the thin films were investigated.

\section{EXPERIMENTAL}

\subsection{Materials and Reagents}

Zinc acetate dihydrate (HmbG Chemicals) and Thiourea (Bendosen) were used as the precursors to synthesize $\mathrm{ZnS}$ nanoparticles (NPs). 3-Aminopropyl triethoxysilane (APTES, 99\%) was purchased from Sigma-Aldrich. Borosilicate 
glass slides $(22 \mathrm{~mm} \times 22 \mathrm{~mm}$, thickness $0.1-1.0 \mathrm{~mm})$ were purchased from HmbG. Alginic acid (Sigma-Aldrich), chitosan (Sigma-Aldrich) and starch (Chemical Reagents, China National Chemical Import and Export Corporation Peking Branch) were used as the biopolymer surfactants. All the reagents were of analytical grade in purity and used without any further purification. Ultrapure water $\left(\sim 18.2 \mathrm{M} \Omega \mathrm{cm}^{-1}, 25^{\circ} \mathrm{C}\right)$ was used in all synthesis processes.

\subsection{Preparation of APTES Functionalised Glass Slides}

Glass slides were functionalised with APTES for the coating of ZnS NPs based on the method reported by Lim et al. ${ }^{20}$ First, the glass slides were cleaned with the piranha solution, which was a mixture of sulphuric acid and hydrogen peroxide with the ratio of 3:1. They were immersed into the solution for $1 \mathrm{~h}$ and next rinsed with ultra-pure water (UPW). The cleaned glass slides were air-dried prior to immersion in $10 \% \mathrm{v} / \mathrm{v}$ APTES in absolute ethanol for $2 \mathrm{~h}$ for amine functionalisation via the silanisation process. Then, they were rinsed with absolute ethanol to remove any excess APTES on the glass slides surfaces, followed by heat treatment at $120^{\circ} \mathrm{C}$ for $30 \mathrm{~min}$.

\subsection{Sample Preparation}

\subsubsection{Synthesis of $\mathrm{ZnS}$ NPs suspension}

ZnS NPs were synthesised based on the method reported by Shahi et al., with some modifications. ${ }^{13}$ An amount of $0.55 \mathrm{~g}$ zinc acetate dihydrate was added into the $50 \mathrm{ml}$ of UPW and stirred continuously until a homogeneous solution was obtained. Subsequently, $0.19 \mathrm{~g}$ of thiourea was added to the solution, which was then kept under vigorous stirring for $2 \mathrm{~h}$.

The chemical process can be described using the following chemical reactions:

$$
\begin{aligned}
& \mathrm{Zn}\left(\mathrm{CH}_{3} \mathrm{COO}\right)_{2} \cdot 2 \mathrm{H}_{2} \mathrm{O} \rightarrow \mathrm{Zn}^{2+}+2\left(\mathrm{CH}_{3} \mathrm{COO}\right)^{-} \\
& \mathrm{Zn}^{2+}+2 \mathrm{OH}^{-} \rightarrow \mathrm{Zn}(\mathrm{OH})_{2} \\
& \mathrm{SC}(\mathrm{NH})_{2}+\mathrm{OH} \rightarrow \mathrm{SH}^{-}+\mathrm{CH}_{2} \mathrm{~N}_{2}+\mathrm{H}_{2} \mathrm{O} \\
& \mathrm{SH}^{-}+\mathrm{OH}^{-} \rightarrow \mathrm{S}^{2-}+\mathrm{H}_{2} \mathrm{O} \\
& \mathrm{SC}\left(\mathrm{NH}_{2}\right)_{2}+2 \mathrm{OH}^{-} \rightarrow \mathrm{S}^{2-}+\mathrm{CH}_{2} \mathrm{~N}_{2}+2 \mathrm{H}_{2} \mathrm{O}
\end{aligned}
$$


Overall reactions:

$$
\begin{aligned}
& \mathrm{Zn}\left(\mathrm{CH}_{3} \mathrm{COO}\right)_{2} \cdot 2 \mathrm{H}_{2} \mathrm{O}+\mathrm{SC}\left(\mathrm{NH}_{2}\right)_{2}+2 \mathrm{OH}^{-} \rightarrow \mathrm{ZnS}+2 \mathrm{CH}_{3} \mathrm{COO}^{-}+ \\
& \mathrm{CH}_{2} \mathrm{~N}_{2}+4 \mathrm{H}_{2} \mathrm{O} \\
& \mathrm{Zn}^{2+}{ }_{\text {(aq) }}+\mathrm{S}^{2-}{ }_{(\text {aq) }} \rightarrow \mathrm{ZnS}
\end{aligned}
$$

\subsubsection{Synthesis of $\mathrm{ZnS}$ NPs suspension with surfactant}

The synthesis method was similar to synthesising ZnS NPs as detailed in Section 2.3.1, except for the addition of starch, alginic acid and chitosan were added into the $\mathrm{ZnS}$ suspension as the surfactants. First, zinc acetate dihydrate was added into $50 \mathrm{ml}$ of UPW water. Then, $0.19 \mathrm{~g}$ of thiourea was added to the mixture under stirring, whereby the solution was continuously stirred for the following $2 \mathrm{~h}$. An amount of $0.05 \mathrm{~g}$ of the biopolymer (i.e., starch, alginic acid and chitosan) was next added into the solution which altered the concentration of the surfactant to $0.1 \%$ $\mathrm{w} / \mathrm{v}$. The solution was stirred for $24 \mathrm{~h}$ for the solution achieving its equilibrium.

$$
\mathrm{Zn}^{2+}{ }_{(\mathrm{aq})}+\mathrm{S}^{2-}{ }_{(\mathrm{aq})} \stackrel{\text { surfactant }}{\longrightarrow} \mathrm{ZnS}_{(\mathrm{s})}
$$

\subsubsection{Deposition of $\mathrm{ZnS}$ nanocrystalline thin film}

The ZnS nanocrystalline thin film deposition was carried out by the spin-coating technique using a spin coater (GLICHN Technology T-108 Spin Coater). Small drops of ZnS NPs suspension were dropped on the centre of the APTES functionalised glass slides by using a dropper, spun for $30 \mathrm{~s}$ at $1000 \mathrm{rpm}$ and then heated at $90^{\circ} \mathrm{C}$ after each deposition. This process was repeated until five layers of thin films were deposited on the glass slides. Subsequently, the deposited thin films were annealed in a digital muffle furnace (WiseTherm FH Daihan $1200^{\circ} \mathrm{C}$ ) at $300^{\circ} \mathrm{C}$ for $2 \mathrm{~h}$ to remove any volatile by-products and improve the crystallinity of the thin films. The annealed thin films were next rinsed with deionised water to remove any impurities on the thin film surface and dried in a desiccator until their further use for characterisation process.

\subsection{Characterisation of ZnS Nanocrystalline Thin Film}

Field emission scanning electron microscope (FESEM) images of the thin films were obtained using a FESEM model ZEISS Supra 55VP and energy dispersive X-ray (EDX). X-Ray diffraction (XRD) patterns of the films were produced using an X-ray diffractometer (Model Bruker D8 Advance) via monochromated $\mathrm{CuK} \alpha$ radiation operated at $40 \mathrm{kV}$. The optical properties were studied using 
a photoluminescence (PL) spectrometer (model Perkin Elmer LS 55) and an ultraviolet-visible (UV-Vis) spectrophotometer (model Lambda 650, Perkin Elmer).

\section{RESULTS AND DISCUSSION}

\subsection{FESEM Analysis}

Figure 1(a) shows the FESEM outcomes of the $\mathrm{ZnS}$ thin film without the addition of surfactants for a comparison with $\mathrm{ZnS}$ thin films that were capped with surfactants. The FESEM images revealed that the $\mathrm{ZnS}$ thin film (without surfactant) was composed of spherical nanoparticle size with mean particle sizes ranging from $27 \mathrm{~nm}$ to $36 \mathrm{~nm}$, which were deposited uniformly throughout the glass slides. Figures 1(b-d) exhibit the FESEM images of biopolymers-capped $\mathrm{ZnS}$ thin films. The particle sizes range for all the samples are presented in Table 1. The particle size range of alginic acid-capped $\mathrm{ZnS}$ thin film was within the range or $16 \mathrm{~nm}$ to $23 \mathrm{~nm}$, which was slightly smaller as compared to a $\mathrm{ZnS}$ thin film that lacked surfactant. This is due to the addition of biopolymer as the surfactants, which has greatly limited the growth of the nanoparticles and thereby resulting in smaller and more uniform mean particles sizes. ${ }^{19}$ The largest particles sizes within the range of 20-32 nm were obtained when chitosan was used as the surfactant. The larger particles sizes of $\mathrm{ZnS}$ as compared to $\mathrm{ZnS}$ without surfactant might be attributable to the large molecular weight of chitosan (MW $\sim 50,000 \mathrm{~g} \mathrm{~mol}^{-1}$ to $190,000 \mathrm{~g} \mathrm{~mol}^{-1}$ ). In contrast, the smallest particles sizes were obtained when starch was used as the surfactant and ranged between $9 \mathrm{~nm}$ and $20 \mathrm{~nm}$ as can be seen in Figure 1(d). This could be due to the highly viscous nature of the starch solution that could effectively limited the nucleation and growth of the nanoparticles.

Figure 2 shows the FESEM cross-sectional images and thin film thickness of: $\mathrm{ZnS}$ thin film without surfactant; alginic acid-capped $\mathrm{ZnS}$ thin film; chitosan-capped $\mathrm{ZnS}$ thin film; and starch-capped thin film. The thickness of the $\mathrm{ZnS}$ thin films without surfactant $(223 \mathrm{~nm})$ and the thin films capped with alginic acid $(228 \mathrm{~nm})$ is about the same. Even though the particle sizes of the thin films without surfactant are larger, the coating of alginic acid has added to the thickness of the thin films. From Figure 2(b), it also can be observed that the addition of alginic acid as the surfactant improved the adherence of ZnS NPs on the surface of the glass slides, and that the thin film was well-assembled. This might be due to the characteristics of alginic acid itself as a good binding agent, viscosifier, and stabilising agent. ${ }^{21}$ Its ability of alginic acid as a binder gave rise to the closely packed $\mathrm{ZnS}$ nanocrystalline thin film. Meanwhile, Figure 2(c) shows that the thickness of the 
chitosan-capped $\mathrm{ZnS}$ thin film of $536 \mathrm{~nm}$ which was thicker as compared to $\mathrm{ZnS}$, alginic-acid capped $\mathrm{ZnS}$, and starch-capped $\mathrm{ZnS}$ thin film. This can be explained by the larger particles size of ZnS NPs that have resulted in an increased thickness of the thin film. As can be seen in Figure 2(d), the average thickness for starchcapped $\mathrm{ZnS}$ thin film was observed to be merely $109 \mathrm{~nm}$. The decrease in the thin film thickness was due to the smaller particle sizes of starch-capped ZnS NPs.
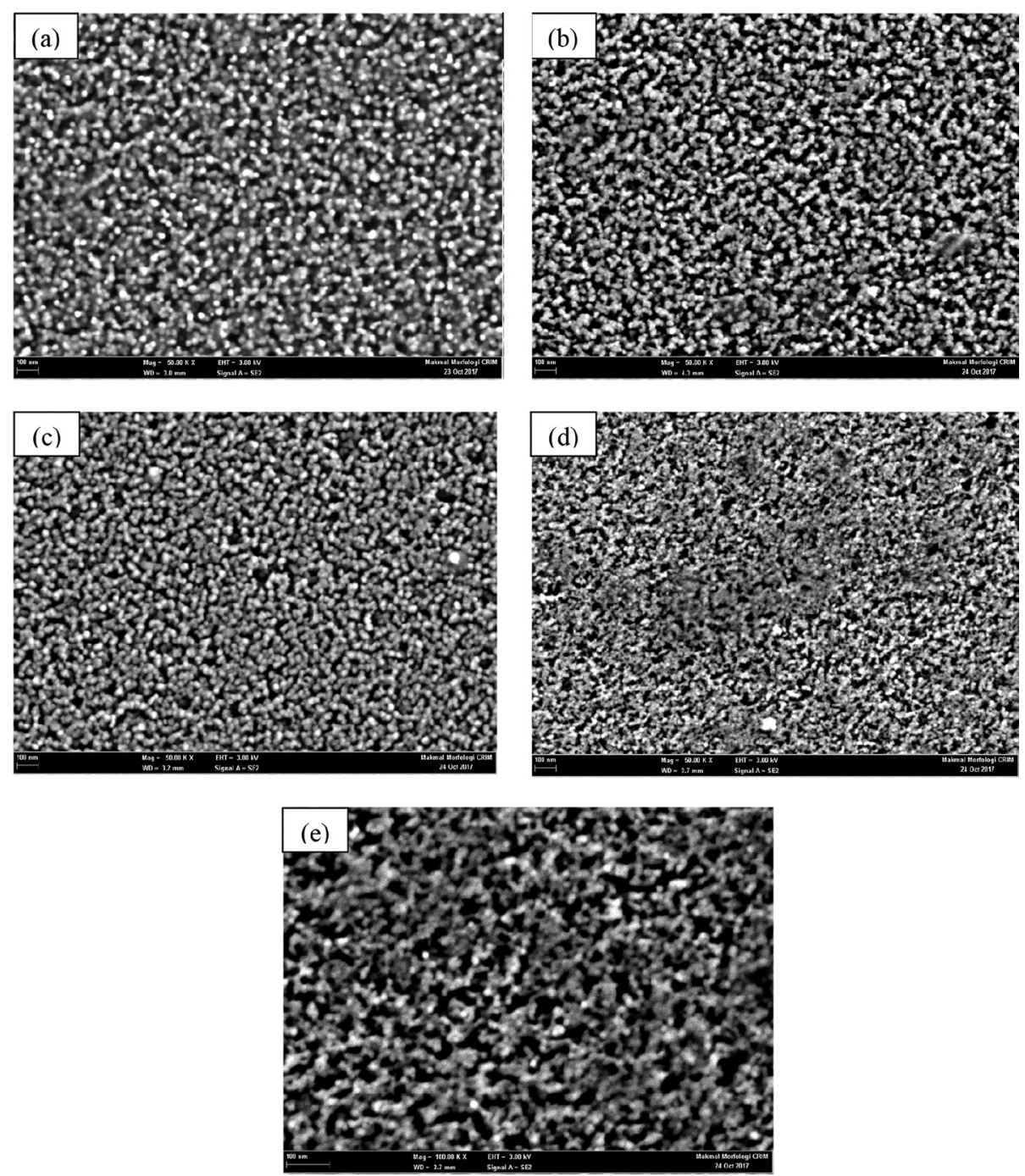

Figure 1: FESEM images of $\mathrm{ZnS}$ films with 50,000X magnification for (a) ZnS without surfactants, (b) alginic acid-capped ZnS, (c) chitosan-capped ZnS, (d) starchcapped $\mathrm{ZnS}$ nanocrystalline thin film, and (e) starch-capped $\mathrm{ZnS}$ nanocrystalline with 100,000X magnification. 
Table 1: Average $\mathrm{ZnS}$ nanoparticle size and thin films thickness.

\begin{tabular}{lccc}
\hline Sample & $\begin{array}{c}\text { Average nanoparticles } \\
\text { size }(\mathrm{nm})\end{array}$ & $\begin{array}{c}\text { Thin film thickness } \\
(\mathrm{nm})\end{array}$ & $\begin{array}{c}\text { Band gap } \\
(\mathrm{eV})\end{array}$ \\
\hline $\mathrm{ZnS}$ & $27-35$ & 223 & 4.85 \\
Alginic acid-capped ZnS & $16-23$ & 228 & 4.83 \\
Chitosan-capped ZnS & $20-32$ & 369 & 4.85 \\
Starch-capped ZnS & $9-21$ & 110 & 4.75 \\
\hline
\end{tabular}
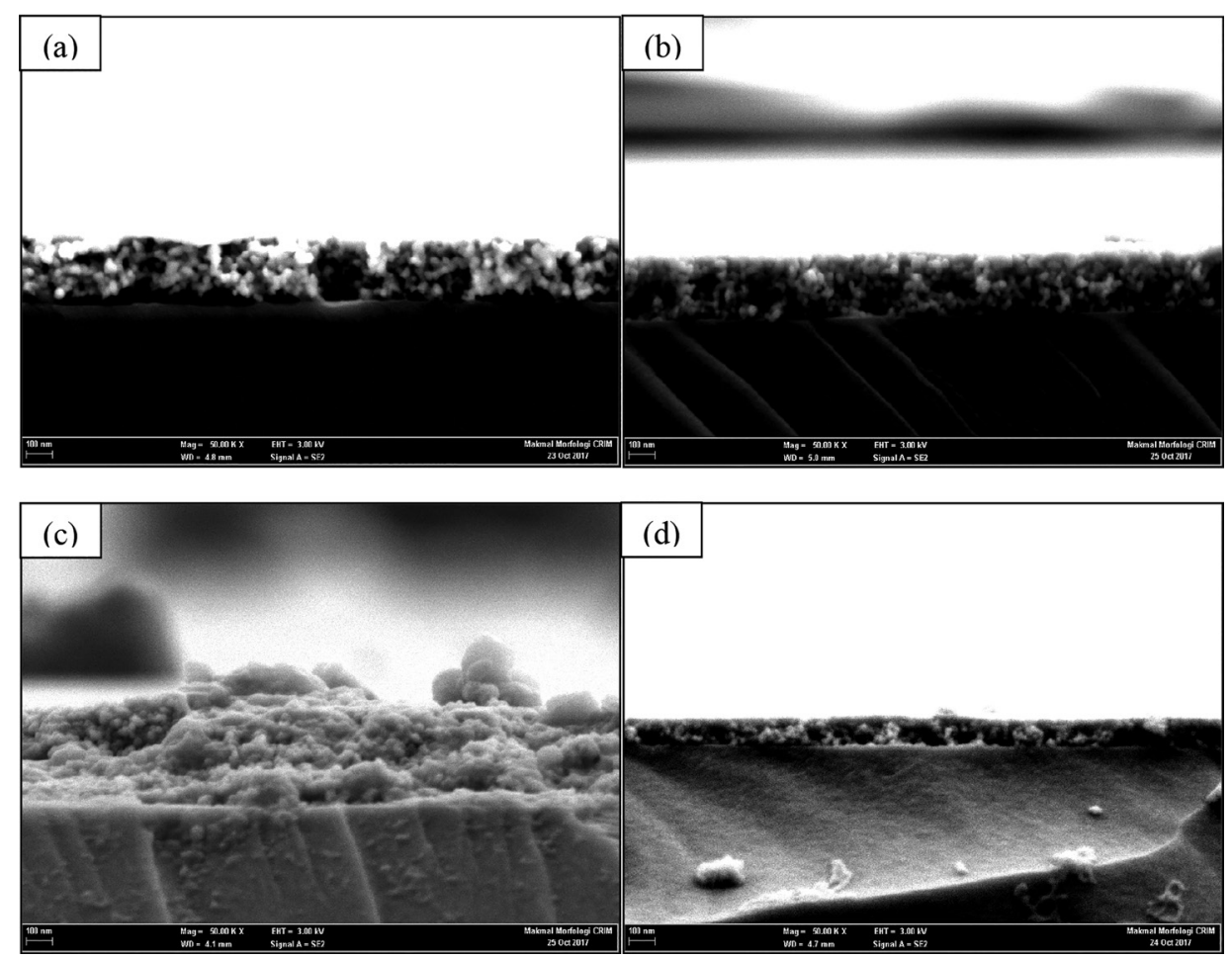

Figure 2: FESEM cross sectional images with 50,000X magnification of (a) $\mathrm{ZnS}$ thin film without surfactant, (b) alginic acid-capped $\mathrm{ZnS}$ thin film, (c) chitosan-capped $\mathrm{ZnS}$ thin film, and (d) starch-capped $\mathrm{ZnS}$ thin film.

\subsection{XRD}

The XRD patterns of the $\mathrm{ZnS}$ thin films are presented in Figure 3. The broad hump observed within the range $2 \theta=15^{\circ}-40^{\circ}$ was due to the amorphous glass substrate. The spectra exhibited three peaks at about $29^{\circ}, 47^{\circ}$ and $57^{\circ}$ which were corresponding to the (111), (220), and (311) crystal planes of the cubic $\mathrm{ZnS}$ phase..$^{23,24}$ 
The average size $(D)$ was calculated using the Debye-Scherrer formula as follows:

$$
D=\frac{0.9 \lambda}{\beta \cos \theta}
$$

where $\lambda$ is the wavelength (Cuk $\alpha$, radiation equals to $1.5406 \mathrm{~nm}$ ), $\theta$ is the Bragg diffraction angle and $\beta$ is the Full Width at Half Maximum (FWHM) of the XRD peak appearing at the diffraction angle $\theta$.
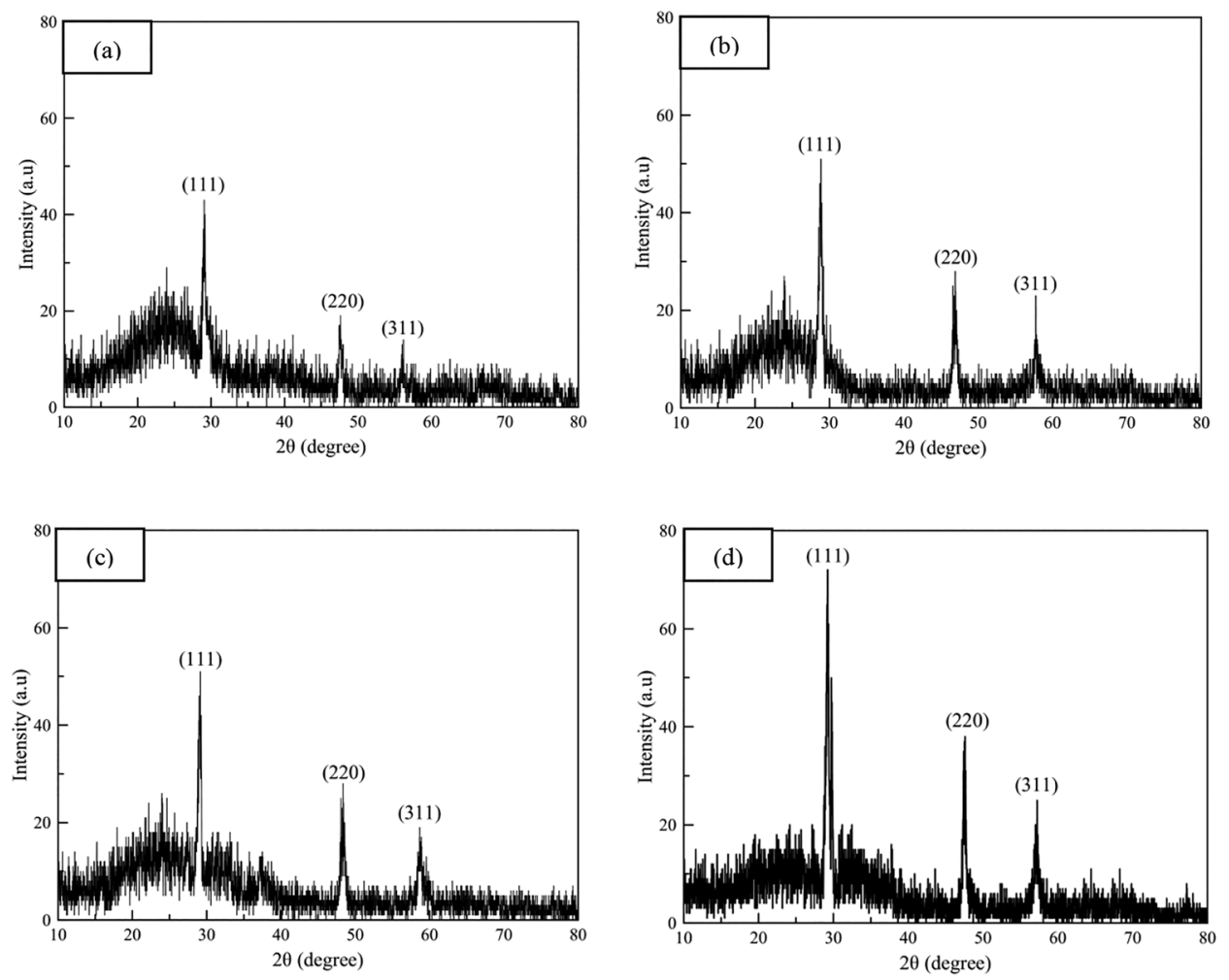

Figure 3: XRD diffractograms of (a) ZnS without surfactants; and ZnS films capped with various types of biopolymer surfactants, i.e., (b) alginic acid, (c) chitosan, and (d) starch.

Figure 3(a) shows that the $\mathrm{ZnS}$ thin film without the presence of surfactant exhibited weaker diffraction peak, which is indicative of the film's low degree of crystallinity. Meanwhile, all the thin films capped with biopolymer surfactants displayed stronger diffraction peak intensity, suggesting their higher degree of crystallinity. ${ }^{22}$ The results obtained from the XRD analysis are summarised in Table 2. The average crystallite sizes of $\mathrm{ZnS}$ nanocrystalline thin films 
were calculated using the Debye-Scherrer equation and varied from $1.71 \mathrm{~nm}$ to $2.98 \mathrm{~nm}$. To reduce error, only the crystallite size for peak (111) of each surfactant-capped thin film was calculated. From the calculations, it can be concluded that the estimated crystallite size of ZnS NPs decreases with the addition of various biopolymers surfactants. It is found that alginic acid, chitosan and starch-capped $\mathrm{ZnS}$ thin film yielded an estimated crystallite size of $2.63 \mathrm{~nm}$, $2.76 \mathrm{~nm}$ and $1.71 \mathrm{~nm}$, respectively. In contrast, $\mathrm{ZnS}$ thin film without a surfactant obtained an estimated crystallite size of $2.98 \mathrm{~nm}$, which was larger than their surfactant-capped counterparts.

Table 2: Results from the XRD of $\mathrm{ZnS}$ thin films with various types of surfactants.

\begin{tabular}{lccccccc}
\hline Samples & Intensity & $\begin{array}{c}2 \theta \\
(\text { degree })\end{array}$ & $\begin{array}{c}\text { FWHM } \\
\text { (degree) }\end{array}$ & $h k l$ & $\mathrm{~d}_{h k l}$ & $\begin{array}{c}\text { Avg. } a \\
(\AA)\end{array}$ & $\begin{array}{c}\text { Crystallite } \\
\text { size }(D)\end{array}$ \\
\hline ZnS & 43 & 29.06 & 0.48 & $(111)$ & 3.17 & 4.86 & 2.98 \\
& 19 & 47.64 & 0.58 & $(220)$ & 1.91 & & \\
& 13 & 56.02 & 1.36 & $(311)$ & 1.64 & & \\
Alginic acid- & 51 & 28.86 & 0.54 & $(111)$ & 3.09 & 4.83 & 2.65 \\
capped ZnS & 28 & 46.92 & 0.56 & $(220)$ & 1.93 & & \\
& 23 & 57.76 & 0.44 & $(311)$ & 1.59 & & \\
Chitosan-capped & 51 & 29.14 & 0.52 & $(111)$ & 3.06 & 4.76 & 2.76 \\
ZnS & 25 & 48.06 & 0.46 & $(220)$ & 1.89 & & \\
& 17 & 58.66 & 1.32 & $(311)$ & 1.57 & & \\
Starch-capped & 64 & 29.14 & 0.84 & $(111)$ & 3.06 & 4.82 & 1.71 \\
ZnS & 35 & 47.42 & 0.36 & $(220)$ & 1.92 & & \\
& 25 & 57.02 & 0.62 & $(311)$ & 1.61 & & \\
\hline
\end{tabular}

\subsection{UV-Vis Analysis}

Figure 4 shows the UV-Vis absorption spectra of the $\mathrm{ZnS}$ thin films that are capped with various biopolymer surfactants. All $\mathrm{ZnS}$ thin films showed excitation peaks at approximately at $250 \mathrm{~nm}$ which was in agreement with Noor et al.'s observation for $\mathrm{ZnS}$ having a great potential to absorb light at a wavelength ranging between $220 \mathrm{~nm}$ and $350 \mathrm{~nm}^{9}$ 


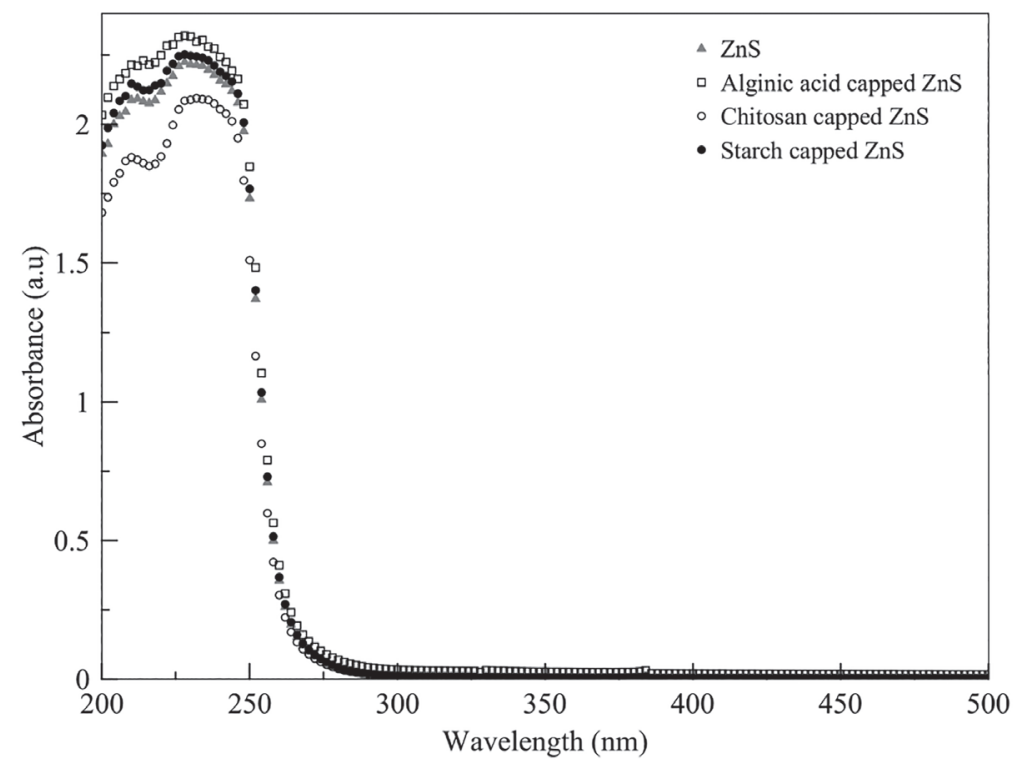

Figure 4: UV-Vis absorption spectra of $\mathrm{ZnS}$ thin films and $\mathrm{ZnS}$ thin films capped with various types of biopolymer surfactants.

Figure 5 shows the optical transmission of the $\mathrm{ZnS}$ thin films that ranged between $200 \mathrm{~nm}$ and $800 \mathrm{~nm}$ as derived from Beer's law equation as shown below, where $\mathrm{A}=$ absorbance, and $\mathrm{T}=$ transmittance.

$$
\begin{aligned}
& \mathrm{A}=\log 10\left(\frac{1}{\mathrm{~T}}\right) \\
& \mathrm{A}=-\log 10(\mathrm{~T}) \\
& \mathrm{T}=10^{(-\mathrm{A})} \\
& \% \mathrm{~T}=\mathrm{T}(100) \\
& \% \mathrm{~T}=100\left(10^{(-\mathrm{A})}\right)
\end{aligned}
$$

The films deposited shows transmittance values of $99 \%, 92 \%, 97 \%$ and $97 \%$ for $\mathrm{ZnS}$ thin film without surfactant, alginic acid-capped $\mathrm{ZnS}$, chitosan-capped $\mathrm{ZnS}$ and starch-capped $\mathrm{ZnS}$ thin films, respectively. The deposited $\mathrm{ZnS}$ thin films deposited exhibit a high optical transmission and anti-reflector properties that may be suitable to be used as anti-reflective materials. ${ }^{3}$ 


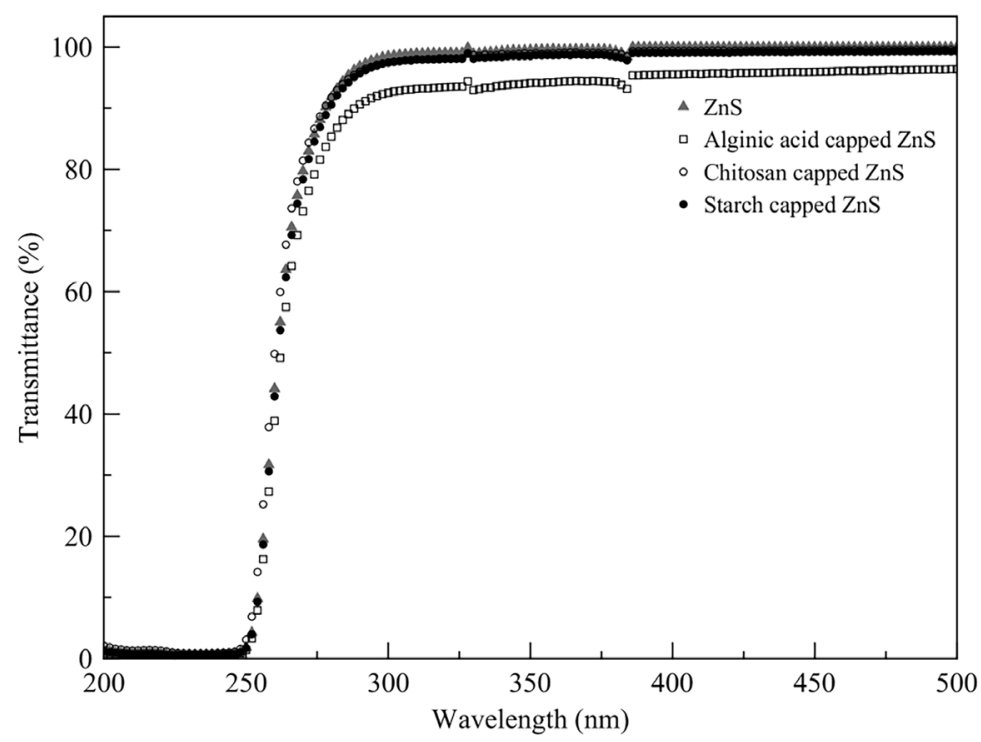

Figure 5: Transmittance spectra of $\mathrm{ZnS}$ nanocrystalline thin films capped with various types of biopolymer surfactants.

Figure 6 exhibits the band gap energy values $\left(E_{\mathrm{g}}\right)$ of various surfactant-capped $\mathrm{ZnS}$ thin films obtained by the UV-Vis spectrophotometer. Since $\mathrm{ZnS}$ is a semiconductor material with a direct band gap, the $E_{\mathrm{g}}$ value can be determined by using the Tauc's formula. The $E_{g}$ value of the films can be evaluated by extrapolating the straight portion to the $h v$ based on the equation below:

$$
(\alpha h v)^{2}=A\left(h v-E_{g}\right)^{m}
$$

where $\alpha$ is the adsorption coefficient, $h v$ is the photon energy $(\mathrm{eV}), A$ is the energy independent constant, $E_{\mathrm{g}}$ is the band gap value and $m$ is the constant that determines the type of optical transmission $(m=2$ for indirect, $m=1 / 2$ for direct transmission). Meanwhile, the adsorption coefficient can be calculated from the transmission spectrum using the following equation:

$$
\alpha=\frac{1}{d \ln (1 / T)}
$$

where $d$ is the thin film thickness and $T$ is the percentage transmission.

The band gap value of $\mathrm{ZnS}$ films without surfactant was observed to be higher $(4.85 \mathrm{eV})$ than its reported band gap value of $3.8 \mathrm{eV}$. The observation was related to the quantum confinement effects caused by the small-grain size of ZnS NPs 
synthesised in this study. ${ }^{25}$ Based on Figure 6, the band gap value is not dependent upon the quantum size or the film thickness. This may be correlated with the types of surfactant added, whereby different types of surfactants have given rise to different band gap values. When alginic acid was used as the surfactant, the band gap value obtained was $4.83 \mathrm{eV}$, whereas, the use of chitosan as the surfactant yielded a band gap value of $4.85 \mathrm{eV}$. Meanwhile, starch-capped $\mathrm{ZnS}$ thin film generated the band gap value of $4.75 \mathrm{eV}$.
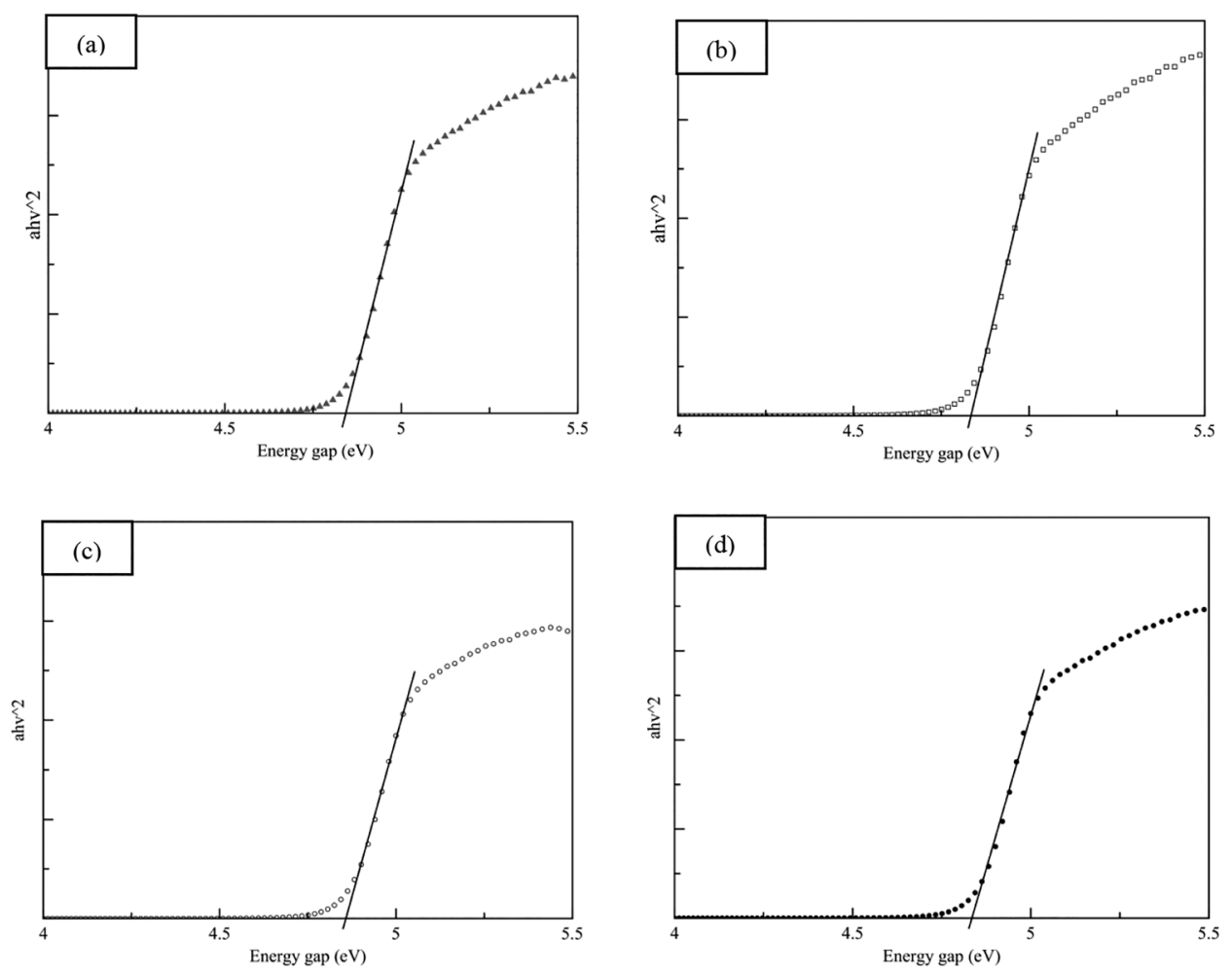

Figure 6: Tauc's plots, i.e., plots of $(\alpha h v)^{2}$ vs. $h v$ for (a) $\mathrm{ZnS}$ (without surfactants), (b) alginic acid capped $\mathrm{ZnS}$ thin film, (c) chitosan capped $\mathrm{ZnS}$ thin film, and (d) starch capped ZnS thin films.

\subsection{Photoluminescence Analysis}

Figure 7 illustrates the room temperature photoluminescence (PL) spectra of all the $\mathrm{ZnS}$ thin films, which were recorded at $300 \mathrm{~nm}$ excitation wavelength. The PL spectra consequently displayed very wide bands ranging between $350 \mathrm{~nm}$ and $700 \mathrm{~nm}$. All the ZnS thin films exhibited the same pattern broad peaks centred at around $470 \mathrm{~nm}, 620 \mathrm{~nm}$ and $690 \mathrm{~nm}$ but each showed different emission intensity. 
The first peak shows that the films are in the blue shift, which is attributable to the zinc vacancies seen at the valence band, while second excitation occurs at the second peak that is not related to the samples, as it could be sourced from the glass slides. ${ }^{26}$ The last peak shows the recombination process that is dependent on the quality of the prepared sample (sample purity), electronic band structure and the properties of the band gap.

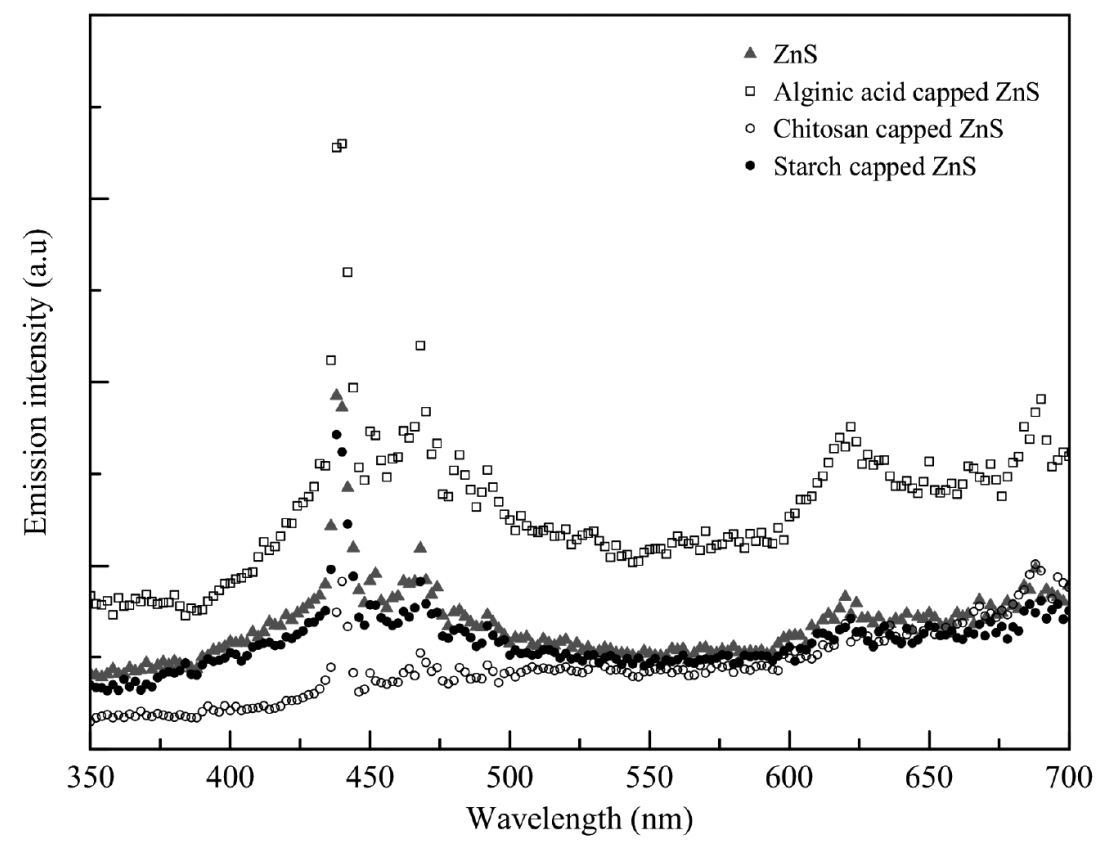

Figure 7: PL spectra of (a) ZnS thin film without surfactant, (b) alginic acid-capped $\mathrm{ZnS}$ thin film, (c) chitosan-capped $\mathrm{ZnS}$ thin film, and (d) starch-capped $\mathrm{ZnS}$ thin films at a $350 \mathrm{~nm}$ excitation wavelength.

\section{CONCLUSION}

Various biopolymers-capped $\mathrm{ZnS}$ nanocrystalline thin films were successfully prepared by the combination of sol-gel and spin coating techniques. XRD patterns confirmed the cubic crystalline structure of $\mathrm{ZnS}$ NPs. The morphology of the thin films was identified using the FESEM analysis, revealing a sphericalshaped nanoparticulate with an average size and thickness that ranged between 20-30 nm and 109-536 nm, respectively. Furthermore, the optical characterisation (UV-Vis absorption) revealed that the band gap of $\mathrm{ZnS}$ nanoparticulate thin films were $4.85 \mathrm{eV}, 4.83 \mathrm{eV}, 4.85 \mathrm{eV}$ and $4.78 \mathrm{eV}$ for $\mathrm{ZnS}$ without surfactant and $\mathrm{ZnS}$ capped with alginic acid, chitosan and starch, respectively. Meanwhile, the PL 
spectra showed broad peaks at approximately $470 \mathrm{~nm}$ and $620 \mathrm{~nm}$. Various types of biopolymer surfactants were observed to be capable of stabilising and impacting the particle sizes of $\mathrm{ZnS}$ NPs as well as indirectly controlling the thickness of the thin films. In conclusion, starch-capped ZnS NPs thin film yielded the best morphological properties, whereby in comparison with the $\mathrm{ZnS}$ thin film without surfactant and other surfactant-capped $\mathrm{ZnS}$ thin films, its nanoparticles and the thin film were more controlled.

\section{ACKNOWLEDGEMENTS}

The financial support by the Ministry of Education (MOE) through the Research Acculturation Grant Scheme RAGS/SG01(1)/1310/2015(04) is gratefully acknowledged. Special thanks to the Faculty of Resource Science and Technology for the analysis work and the Physics Laboratory of the Centre of Pre-University Studies, Universiti Malaysia Sarawak for the laboratory works.

\section{REFERENCES}

1. Farid, H. et al. (2014). Preparation and characterization of $\mathrm{ZnS}$ nanocrystalline thin films by low cost dip technique. J. Mater. Sci. Mater. Electron., 25(5), 2017-2023, https://doi.org/10.1007/s10854-014-1790-9.

2. Kavanagh, Y. \& Cameron, D. C. (2001). Zinc sulfide thin films produced by sulfidation of sol-gel deposited zinc oxide. Thin Solid Films, 398, 24-28. https://doi.org/10.1016/S0040-6090(01)01298-6.

3. Offor, P. O. et al. (2015). Synthesis and characterization of nanocrystalline zinc sulphide thin films by chemical spray pyrolysis. J. Alloy Comp., 650, 381-385, https://doi.org/10.1016/j.jallcom.2015.07.169.

4. Goktas, A. et al. (2012). Preparation and characterisation of thickness dependent nano-structured $\mathrm{ZnS}$ thin films by sol-gel technique. J. Mater. Sci. Mater. Electron., 23(7), 1361-1366, https://doi.org/10.1007/s10854-011-0599-z.

5. Shanmugam, N. et al. (2013). Effect of annealing on the $\mathrm{ZnS}$ nanocrystals prepared by chemical precipitation method. J. Nanomater., Article ID 351798, https://doi.org/10.1155/2013/351798.

6. Ravichandran, K. \& Nedumaran, D. (2011). Synthesis and characterization of zinc sulfide nanoparticles using inert gas condensation technique. Int. J. Mech. Eng. Mater. Sci., 4, 25-31.

7. $\mathrm{Xu}, \mathrm{J}$. F. et al. (1998). Preparation of $\mathrm{ZnS}$ nanoparticles by ultrasonic radiation method. Appl. Phys. A, 66(6), 639-641, https://doi.org/10.1007/s003390050725.

8. Liu, J. et al. (2009). Synthesis of $\mathrm{ZnS}$ nanoparticles via hydrothermal process assisted by microemulsion technique. J. Alloy Comp., 486(1-2), L40-L43, https://doi.org/10.1016/j.jallcom.2009.07.109. 
9. Noor, A. A. et al. (2017). Effect of annealing temperature and spin coating speed on $\mathrm{Mn}$-doped $\mathrm{ZnS}$ nanocrystals thin film by spin coating. J. Nanomater., Article ID 2560436, https://doi.org/10.1155/2017/2560436.

10. Stefan, M. et al. (2013). Synthesis of luminescent zinc sulphide thin films by chemical bath deposition. J. Alloy Comp., 548, 166-172, https://doi.org/10.1016/j. jallcom.2012.09.013.

11. Brahma, S. et al. (2015). Effect of substrates and surfactants over the evolution of crystallographic texture of nanostructured $\mathrm{ZnO}$ thin films deposited through microwave irradiation. Thin Solid Films, 593, 81-90, https://doi.org/10.1016/j. tsf.2015.09.005.

12. Charinpanitkul, T. et al. (2005). Effects of cosurfactant on $\mathrm{ZnS}$ nanoparticle synthesis in microemulsion. Sci. Technol. Adv. Mater., 6(3-4), 266-271, https://doi.org/10.1016/j.stam.2005.02.005.

13. Shahi, A. K. et al. (2011). Surfactant assisted surface studies of zinc sulfide nanoparticles. Appl. Surf. Sci., 257(23), 9846-9851, https://doi.org/10.1016/j. apsusc.2011.06.046.

14. Pawar, N. B. et al. (2012). Effect of surfactant on optical and structural properties of chemically deposited $\mathrm{MoBi}_{2} \mathrm{~S}_{5}$ thin films. New J. Chem., 36(9), 1807-1812, https://doi.org/10.1039/c2nj40341b.

15. Dhanam, M. et al. (2009). Analysis of $\mathrm{ZnS}$ nanoparticles prepared by surfactant micelle-template inducing reaction. Chal. Lett., 6(12), 713-722.

16. Mehta, S. K. et al. (2009). Effect of cationic surfactant head groups on synthesis, growth and agglomeration behavior of $\mathrm{ZnS}$ nanoparticles. Nanosc. Res. Lett., 4(10), 1197, https://doi.org/10.1007/s11671-009-9377-8.

17. Ayodhya, D. et al. (2013). Synthesis, characterization of $\mathrm{ZnS}$ nanoparticles by coprecipitation method using various capping agents: Photocatalytic activity and kinetic study. IOSR-JAC, 6(1), 101-109, https://doi.org/10.9790/5736-0610109.

18. Senapati, U. S. \& Sarkar, D. (2015). Synthesis and characterization of biopolymer protected zinc sulphide nanoparticles. Superlatt. Microstr., 85, 722-733, https://doi.org/10.1016/j.spmi.2015.06.040.

19. Sreejith, L., Nair, S. M. \& George, J. (2010). Biopolymer surfactant interactions. In Elnashar, M. (ed), Biopolymers. London: InTech Open, 612. https://doi. org/10.5772/10272.

20. Lim, L. S. et al. (2017). A novel silver nanoparticles-based sensing probe for the detection of Japanese Encephalitis virus antigen. Sains Malays., 46(12), 24472454, https://doi.org/10.17576/jsm-2017-4612-21.

21. Donati, I. \& Paoletti, S. (2009). Material properties of alginates. In Rehm, B. H. A. (ed.), Alginates: Biology and applications. Berlin: Springer, 1-53. https://doi. org/10.1007/978-3-540-92679-5_1.

22. Al-khayatt, A. H. O. \& Jaafer, M. D. (2014). Characteristics of nanocrystalline ZnS thin films grown on glass with different $\mathrm{Zn}$ ion concentrations by $\mathrm{CBD}$ technique. J. Appl. Phys., 6, 27-35, https://doi.org/10.9790/4861-06132735.

23. Zein, R. \& Alghoraibi, I. (2014). Effect of deposition time on structural and optical properties of $\mathrm{ZnS}$ nanoparticles thin films prepared by CBD method. Int. J. Chemtech. Res., 6(5), 3220-3227. 
24. Chen, H. \& Gui, L. (2015). Preparation of ZnS modified PHBV Film by chemical bath deposition method. Proceed. Int. Conf. Chem. Mater. Food Eng., 3-6, https://doi.org/10.2991/cmfe-15.2015.1.

25. Sartale, S. D. et al. (2005). Preparation of nanocrystalline $\mathrm{ZnS}$ by a new chemical bath deposition route. Thin Solid Films, 480, 168-172, https://doi.org/10.1016/j. tsf.2004.11.054.

26. Denzler, D., Olschewski, M. \& Sattler, K. (1998). Luminescence studies of localized gap states in colloidal $\mathrm{ZnS}$ nanocrystals. J. Appl. Phys., 84(5), 28412845, https://doi.org/10.1063/1.368425. 